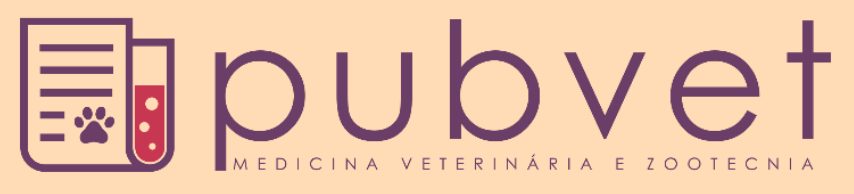

ISSN $1982-1263$

https://doi.org/10.31533/pubvet.v13n4a320.1-8

\title{
Hidroterapia e/ou eletroterapia no reparo tecidual de ratos desnervados
}

\author{
Jamila Cristina Baptistella ${ }^{1 *} \bullet$, Juliana de Carvalho Apolinário Coêlho ${ }^{2 *}$, José Carlos Silva Camargo \\ Filho $^{3 \oplus}$, Roberto Carvalhal ${ }^{1}{ }^{\ominus}$, Mário Jefferson Quirino Louzada ${ }^{\oplus}$, Tereza Cristina Cardoso ${ }^{4} \bullet$
}

${ }^{1}$ Departamento de Apoio, Produção e Saúde Animal, Faculdade de Medicina Veterinária, UNESP, Araçatuba/SP, Brasil. ${ }^{\#}$ Bolsista CAPES ${ }^{2}$ Doutoranda do Programa Multicêntrico de Pós-Graduação em Ciências Fisiológicas, Faculdade de Odontologia, UNESP, Araçatuba, SP. Bolsista do CNPq, Brasil ${ }^{3}$ Departamento de Fisioterapia. Faculdade de Ciências e tecnologia de Presidente Prudente - UNESP.

${ }^{4}$ Laboratório de Virologia animal e cultura celular de Medicina Veterinária, UNESP, Araçatuba/SP, Brasil.

Endereço para correspondência: Rua Eleutério Francisco Ferreira, n. 100, Casa 1, Joinville/SC, CEP 89227-493. Aos cuidados de Prof. Adjunto Mário Jefferson Quirino Louzada. E-mail: Jamila.baptistella@unisociesc.com.br

Resumo. Traumatismos que acarretam em distúrbios nos nervos resultando em atrofia, afetando tanto fibras musculares lentas quanto rápidas, resultando na diminuição do diâmetro destas fibras e da força muscular. As principais características das alterações no sistema musculoesquelético dizem respeito à diminuição da massa muscular e óssea. As relações existentes entre atividade de modelamento do osso e ação bombeadora dos músculos podem ser calculadas a partir de experimentos com denervação. Em contrapartida à atrofia muscular, este estudo tem como hipótese que a denervação causa atrofia muscular, e que a eletroterapia e a hidroterapia podem restaurar os danos causados por esta denervação. Assim, é objetivo deste estudo testar estas hipóteses pela histomorfometria dos músculos extensor digital longo e flexor digital superficial e por análises biomecânicas e densitométricas das tíbias correspondentes. Foram utilizados 40 ratos Wistar, dividido em: GC-controle; GD-submetido à denervação; GH-submetido à denervação e hidroterapia; GHE-submetido à denervação, hidroterapia seguida de eletroterapia e GE-submetido à denervação e eletroterapia. Foram realizadas 20 sessões de tratamento para cada grupo, 5 sessões por semana. Os animais foram sacrificados e tiveram seus membros pélvicos dissecados para observar a massa, diâmetro e quantidade de fibras musculares e, também densidade, conteúdo mineral e parâmetros mecânicos de tíbia. Todos os dados passaram por análise estatística descritiva - Média, Desvio Padrão e Coeficiente de Variância ANOVA e teste de Tukey para comparação dois a dois, com nível de significância de 5\%. Pode-se concluir diante da metodologia aplicada, que a denervação provoca diminuição nas propriedades musculares, causando atrofia muscular, no entanto não acarreta perdas nas propriedades ósseas e que o uso da eletroterapia foi capaz de reverter a quantidade das fibras.

Palavras-chave: ratos wistar, músculo extensor digital longo, flexor digital superficial, tíbia, nervo isquiático

\section{Hydrotherapy and/or electrotherapy for tissue repair in rats denervated}

\begin{abstract}
Trauma that resume in nerve disorder resulting in atrophy, affecting slow muscle fibers as well as fast ones, resulting in the reduction of the diameter of these fibers and the muscle strength. The main characteristics of the changes in the musculoskeletal system are related to the reduction of the muscle and bone mass. The relationship existing between bone modeling and the pumping action of muscles can be calculated from denervation experiments. In contrast to muscle atrophy, this study believes that denervation causes muscle atrophy and believes electrotherapy and hydrotherapy can repair de damages caused by this denervation. So, the objective of this study is to test the hypothesis above through histomorphometry of long digital extensor muscles and superficial digital flexor and
\end{abstract}


through biomechanical and densitometric analysis of the corresponding tíbia. We used 40 Wistar rats divided in: GC-control; GD-subjected to denervation; GH-subjected to denervation and hydrotherapy; GHE-subjected to denervation, hydrotherapy followed by electrotherapy and GE-subjected to denervation and electrotherapy. Each group had 20 treatment sessions, 5 per week. The animals were sacrificed and had their hindlimbs dissected to observe the mass, diameter and the quantity of muscle fibers and also density, mineral content and tibia mechanical parameters. All data passed by descriptive statistical analysis-average, Standard Deviation and Variance - ANOVA and Turkey Test to compare two by two, with a significance level of $5 \%$. It can be concluded on the methodology aplied that denervation brings decrease in muscle properties, causing muscle atrophy, but it doesn't entail losses in bone properties and the use of electrotherapy was able to reverse the fiber quantity.

Key words: Wistar rats, long digital extensor muscles, superficial digital flexor, tíbia, sciatic nerve

\section{Hidroterapia y/o electroterapia en la reparación del tejido de ratones desnervados}

Resumen. Traumatismos que acarrean en disturbios en los nervios resultando en atrofia, afectando tanto fibras musculares lentas como rápidas, resultando en la disminución del diámetro de estas fibras y de la fuerza muscular. Las principales características de las alteraciones en el sistema musculoesquelético se refieren a la disminución de la masa muscular y ósea. Las relaciones existentes entre actividad de modelado del hueso y acción bombeadora de los músculos pueden ser calculadas a partir de experimentos con denervación. En contrapartida a la atrofia muscular, este estudio tiene como hipótesis que la denervación causa atrofia muscular, y que la electroterapia y la hidroterapia pueden restaurar los daños causados por esta denervación. Así, es objetivo de este estudio probar estas hipótesis por la histomorfometría de los músculos extensor digital largo y flexor digital superficial y por análisis biomecánicos y densitométricos de las tibias correspondientes. Se utilizaron 40 ratas Wistar, dividido en: GC-control; GD-sometido a la denervación; GH-sometido a la denervación e hidroterapia; GHE-sometido a la denervación, hidroterapia seguida de electroterapia y GE-sometido a la denervación y electroterapia. Se realizaron 20 sesiones de tratamiento para cada grupo, 5 sesiones por semana. Los animales fueron sacrificados y tuvieron sus miembros pélvicos disecados para observar la masa, diámetro y cantidad de fibras musculares y, también, densidad, contenido mineral y parámetros mecánicos de tibia. Todos los datos pasaron por análisis estadístico descriptivo - Media, Desviación Estándar y Coeficiente de Varianza - ANOVA y test de Tukey para comparación dos a dos, con un nivel de significancia del 5\%. Se puede concluir ante la metodología aplicada, que la denervación provoca disminución en las propiedades musculares, causando atrofia muscular, sin embargo, no acarrea pérdidas en las propiedades óseas y que el uso de la electroterapia fue capaz de revertir la cantidad de las fibras.

Palabras clave: ratas wistar, músculo extensor digital largo, flexor digital superficial, tibia, nervio isquiático

\section{Introdução}

Há pouco tempo, o curso da dor crônica e das moléstias degenerativas dos animais conduzia-os para a eutanásia. Em virtude dos avanços de técnicas terapêuticas na Medicina Veterinária, estes animais estão vivendo mais, apesar das várias doenças que são capazes de causar sintomas degenerativos. Traumatismos, como quedas, atropelamentos, entre outros que causam distúrbios em nervos pela compressão, esmagamento ou até mesmo ruptura total do mesmo, levando à perda da musculatura, ou seja, uma atrofia muscular.

As principais características das alterações no sistema musculoesquelético dizem respeito à diminuição da massa muscular e óssea, pois há uma grande associação entre essas forças. Evidências 
significativas de que um ambiente destituído de estímulo mecânico produza efeitos diretos na estrutura e funções ósseas, principalmente, naqueles que servem de apoio para o peso corporal como, por exemplo, o fêmur e a tíbia (Apolinário et al., 2011; Riso et al., 2010). As relações existentes entre atividade de modelamento do osso e ação bombeadora dos músculos sobre a circulação e a velocidade do fluxo sanguíneo através das extremidades podem ser calculadas a partir de experimentos com denervação (Guerrino et al., 1996).

Em contrapartida à atrofia muscular, de acordo com Velho et al. (2006) a fisioterapia é uma alternativa médica que possui técnicas próprias não-invasivas indispensáveis para reabilitação de pacientes acometidos por diversos tipos de enfermidades. A hidroterapia é um tratamento fisioterápico efetivo para disfunções músculo esquelético como a atrofia muscular, mostrando influência severa em vários sistemas do corpo, proporcionando a excelentes benefícios no sistema músculo esquelético, neurológico e cardiovascular principalmente (Medeiros et al., 2004). Segundo Evangelista et al. (2003), para se restabelecer as funções normais de um músculo, quando sua força apresenta diminuída, usa-se programas de fortalecimento muscular, como a eletroestimulação. A eletroestimulação contínua também é um tratamento fisioterápico efetivo para as disfunções músculo esquelético como a atrofia muscular, tendo como objetivo em músculos denervados exercitá-los eletricamente para que estes se mantenham o mais saudável possível, enquanto os axônios lesados se regenerem e voltem a inervá-los (Pedro \& Oliveira, 2009; Polônio et al., 2010).

\section{Objetivo}

Este estudo tem como hipótese que a denervação causa atrofia muscular e gera alternações nas propriedades ósseas, e que a eletroterapia e a hidroterapia podem restaurar os danos causados por esta denervação. Assim, é objetivo deste estudo testar estas hipóteses pela histomorfometria dos músculos extensor digital longo e flexor digital superficial e por análises biomecânicas e densitométricas das tíbias correspondentes.

\section{Material e métodos}

O experimento está de acordo com os princípios éticos da Experimentação Animal (COBEA) e foi aprovado pela Comissão de Ética na Experimentação Animal (CEEA) em 17/11/2010 de acordo com o protocolo 2010-008755, Faculdade de Odontologia/UNESP/Araçatuba-SP.

Foram estudados 40 ratos Wistar, com 3 meses de idade, machos. Os animais foram mantidos em ambiente climatizado, fotoperiódicos de $12 \mathrm{~h}$ claro/escuro e alimentados com ração (Purina para roedores) e água à vontade.

Os animais foram divididos de forma aleatória em 5 grupos $(n=8)$ contendo 4 animais por caixa: (GC) controle; (GD) submetido à denervação sem tratamento fisioterápico; (GH) submetido à denervação e hidroterapia; (GE) submetido à denervação e eletroterapia e (GHE) submetido à denervação, hidroterapia e eletroterapia.

Foram realizadas 20 sessões de tratamento após $24 \mathrm{~h}$ passadas da cirurgia (hidroterapia e/ou eletroterapia) para cada grupo, sendo 5 sessões por semana e $24 \mathrm{~h}$ após a última sessão os animais foram eutanasiados por deslocamento cervical, tiveram seus membros pélvicos dissecados para observação de massa, diâmetro e quantidade de fibras musculares, além da densidade e conteúdo mineral da tíbia. $\mathrm{O}$ GC permaneceu em gaiola durante todo o tempo experimental correspondente aos outros grupos. Os grupos GD, GH, GE e GHE foram anestesiados com Ketamina (30 mg/Kg) e Xilazina (3 mg/kg) para o procedimento cirúrgico foi realizada incisão de aproximadamente $1,5 \mathrm{~cm}$ sobre a pele e separado os músculos bíceps femoral e semitendinoso para a visualização do nervo isquiático que foi exposto e submetido a 4 pinçamentos consecutivos (intervalo de 20 segundos cada), com pinça mosquito (Erwin $\mathrm{Guth}^{\circledR}$ - Brasil), depois foi realizada a sutura apenas na pele. Após $24 \mathrm{~h}$, teve início a fisioterapia para os grupos GH, GE e GHE. A sessão para os tratamentos foi de 20 minutos para cada animal.

Após o término do período experimental, foram retiradas as amostras (músculos e ossos), as mesmas foram analisadas e feitas às comparações entre os grupos, para observar se houve benefícios na massa, 
diâmetro e quantidade de fibras, além da DMO e CMO, obtidos pela fisioterapia dentro de 20 sessões. Após 24 horas da cirurgia, deu-se início aos tratamentos de hidroterapia e eletroterapia. Para a hidroterapia foi utilizada uma piscina pequena, com quantidade de água suficiente para que os ratos nadassem, sem nenhum contato com o fundo da piscina. A água estava aquecida a $36^{\circ} \mathrm{C}$. Para a eletroterapia, o aparelho utilizado foi o physiotonus four (Bioset ${ }^{\circledR}$ - Brasil), com eletrodos de $1 \mathrm{~cm}^{2}$, foi utilizada a corrente FES na frequência de $10 \mathrm{~Hz}$, fase de $300 \mu$ s e intensidade de $10 \mathrm{~mA}$ no total (Fernandes et al., 2005), sendo que foi iniciado com baixa intensidade e aumentado a cada 2 minutos $2 \mathrm{~mA}$. Os eletrodos foram colocados na porção cranial e caudal de cada músculo, fixados com gel e esparadrapo para que permanecessem no local durante todo o período da sessão. Os animais foram imobilizados com contensores Insight ${ }^{\circledR}$ (Contensores EB 285M - Contensor para Rato de 0 - 500 gramas Insight $^{\circledR}$ - Brasil) próprios para ratos a fim de que não ocorressem acidentes, então realizada as sessões.

\section{Massa Corpórea dos ratos}

A massa corpórea foi avaliada no início do experimento e no momento da eutanásia com balança digital de precisão (Balança Toledo ${ }^{\circledR}$ - Brasil).

\section{Congelamento e processamento dos músculos}

Para o processo de congelamento dos músculos, os mesmos foram pesados balança digital de precisão, e logo em seguida passados em talco para a retirada do excesso de líquidos. Após o procedimento, foi retirado o ventre muscular e imersos em nitrogênio líquido por 5 minutos, período após o qual era armazenado em tubos criogênicos que também permaneciam em nitrogênio líquido para que no momento em que os músculos congelados entrassem em contado com os tubos, eles estivessem na mesma temperatura, logo de imediato foram armazenados em freezer a $-80{ }^{\circ} \mathrm{C}$. Em seguida, os mesmos foram encaminhados para a Universidade Estadual Paulista Júlio de Mesquita Filho (Faculdade de Ciências e Tecnologia - Presidente Prudente, Laboratório de Histologia) em caixas de isopor contendo nitrogênio líquido, para o seu processamento. $\mathrm{O}$ aparelho utilizado para o mesmo foi o Micrótomo (Micron HM 505 E - Cryostat Microtome Freezing da eBay ${ }^{\circledR}$ - EUA), trabalhando sempre dentro do aparelho em uma temperatura entre -20 a $-18^{\circ} \mathrm{C}$. Após o fatiamento, foi feita análise histológica da região média, foram observados diâmetro e quantidade de fibras musculares. $\mathrm{O}$ procedimento para corar as lâminas iniciou-se com o formol-cálcio e depois coradas com hematoxilina/eosina. Todo o procedimento de corar as lâminas, as mesmas foram mantidas em descanso para depois serem observadas ao microscópio.

Para a avaliação de contagem e diâmetro das fibras musculares, foi utilizado o programa NISElements D3.0 (NIS Elements D3.0 - Nikon ${ }^{\circledR}$ - EUA) acoplado ao microscópio óptico Nicon SP7 (Nicon SP7 - Prolab ${ }^{\circledR}$ - Brasil), com aumento de 40x, onde as lâminas foram fotografadas. Foram utilizadas seis lâminas por animal, escolhidas três campos de cada lâmina e feita a contagem e medição do diâmetro, totalizando dezoito campos. Após esse procedimento foi realizada uma média para cada animal.

\section{Parâmetros ósseos}

Depois da eutanásia, os membros pélvicos foram dissecados e as tíbias desarticuladas, removidas e limpas dos tecidos moles circundantes para análises densitométrica e biomecânica. A densidade mineral óssea foi realizada por densitômetro ósseo padrão e a resistência óssea foi determinada por ensaio mecânico destrutivo.

As tíbias de ratos foram submetidas à análise da densidade mineral óssea - DMO $\left(\mathrm{em} \mathrm{g} / \mathrm{cm}^{2}\right)$, área $\left(\mathrm{cm}^{2}\right)$ e conteúdo mineral ósseo - $\mathrm{CMO}(\mathrm{g})$ medidos em toda a tíbia com o densitômetro (Densitômetro - DPX-Alpha Lunar $^{\circledR}$ - Brasil (pertencente ao Departamento de Apoio, Produção e Saúde Animal FOA/UNESP).

Para os ensaios mecânicos, flexão em três pontos, foi utilizada a máquina Universal de Ensaio (EMIC $^{\circledR}$ - Brasil, do Departamento de Materiais Dentários da FOA/UNESP-Araçatuba). A carga de $2000 \mathrm{~N}$ foi aplicada a uma velocidade de $5 \mathrm{~mm} / \mathrm{min}$ e registrada automaticamente pelo sistema computacional pertencente à máquina. Todos os ensaios foram realizados em condições semelhantes. 
$\mathrm{Na}$ análise biomecânica, foi avaliada a resistência óssea, analisando a força máxima admitida pelo tecido ósseo. A distância do vão de apoio foi de $20 \mathrm{~mm}$.

\section{Análise estatística}

Foi realizada análise estatística descritiva - média, desvio padrão e coeficiente de variância. Todos os dados passaram por análise de variância - ANOVA e teste de Tukey para comparação dois a dois, com nível de significância de 5\%.

\section{Resultados e discussão}

No momento seguinte a cirurgia para denervação em que os animais se recuperaram da anestesia, foi nítida a eficiência da denervação, pois eles perderam seus movimentos de tíbia e dígitos, fazendo seu movimento devido à articulação coxofemoral que não foi afetada devido ao processo. Os mesmos arrastavam o membro ao solo durante a locomoção e os dígitos. Nota-se perda da tensão e a propriocepção digitais e flacidez dos músculos dos membros denervados, observou-se perda na sensibilidade superficial e profunda após serem denervados, contudo não perderam o apoio ao solo, justificando a manutenção de algumas variáveis ósseas, em nosso estudo.

Segundo Evangelista et al. (2003), nos grupos que foram realizados eletroestimulação em (humanos), os pacientes não relataram dores musculares. Desta maneira e observando os animais que receberam eletroterapia, podemos dizer que os animais não passaram por dores, pois não apresentaram alterações comportamentais, não se tornaram agressivos e não apresentaram ruídos ou gemidos. Os resultados deste trabalho estão de acordo com os de Fernandes et al. (2005), Durigan et al. (2006) e Pedro \& Oliveira (2009) que observaram atrofia muscular maior no grupo denervado (Figura 4GD) com perda rápida de massa muscular, tendo a eletroestimulação (Figura 4GE) minimizado ou prevenido a atrofia muscular. No presente trabalho, a eletroestimulação não aumentou a massa muscular e o diâmetro das fibras musculares, entretanto, houve aumento no número de fibras musculares para valores semelhantes aos do grupo controle, tanto no GHE como no GE (Figuras 1, 2 e 3).

O aumento no número de fibras musculares sugere que a eletroterapia foi capaz de gerar estímulo de contração elétrica suficiente para tratamento da atrofia em 20 dias (tempo de tratamento utilizado nesta pesquisa). Todavia, não foi encontrado aumento na massa muscular, diferindo do trabalho realizado por Rodrigues et al. (2011) que observaram um aumento da massa no músculo sóleo após sete dias consecutivos de eletroestimulação, esta divergência pode ser justificada, pois foi utilizada uma frequência de $50 \mathrm{~Hz}$, enquanto que no presente estudo foi utilizada frequência de $10 \mathrm{~Hz}$.

$\mathrm{O}$ aumento no número de fibras musculares para valores semelhantes aos do grupo controle (figura 4GC), tanto no GHE (Figura 4GHE) como no GE (Figura 4GE), enfatiza uma melhora do quadro, pois, a eletroestimulação tem, em curto prazo, capacidade em reduzir nível de degradação proteica muscular e estimular produção de fatores de crescimento, como as células satélites, que são capazes de se diferenciar e se fundir permitindo assim o aumento do número de fibras e formar novas fibras, ou seja, estão envolvidas no crescimento muscular normal, assim como na regeneração após lesão ou doença (Seale \& Rudnicki, 2000).

A hidroterapia (Figura 4GH) elevou a quantidade de massa muscular para nível do grupo controle quando nos referimos (Figura 1), mas não foi suficiente para reverter a perda de diâmetro causada pela denervação (Figura 3) e não foi eficaz no aumento do número de fibras musculares (Figura 2). Sugerindo que o aumento da massa muscular pode ser devido ao aumento na quantidade de tecido conjuntivo, justificado por trabalho de Salmons et al. (2005) afirmam que a pesagem da massa é uma técnica simples, porém, reflete indiretamente o trofismo das fibras, visto que também é influenciada por outros fatores como a proliferação do tecido conjuntivo. Ao comparar os grupos GE e GHE com o grupo GH, identifica-se que o GH apresenta maior diâmetro dos músculos e maior massa muscular, mostrando que a hidroterapia foi eficaz para minimizar a perda acentuada ocorrida nos demais grupos, pois durante o tratamento de eletroterapia o animal fica em repouso. 


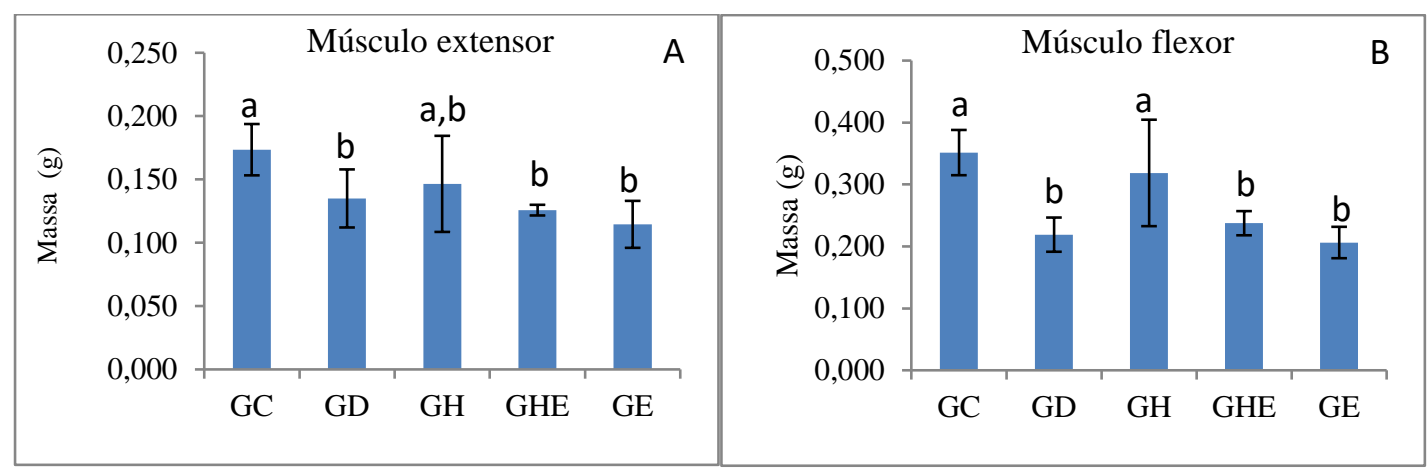

Figura 1. Massa do músculo extensor digital longo (A) e flexor digital superficial (B) dos grupos estudados média e desvio padrão. Médias seguidas de letras diferentes são diferentes $(\mathrm{P}>0,05)$.

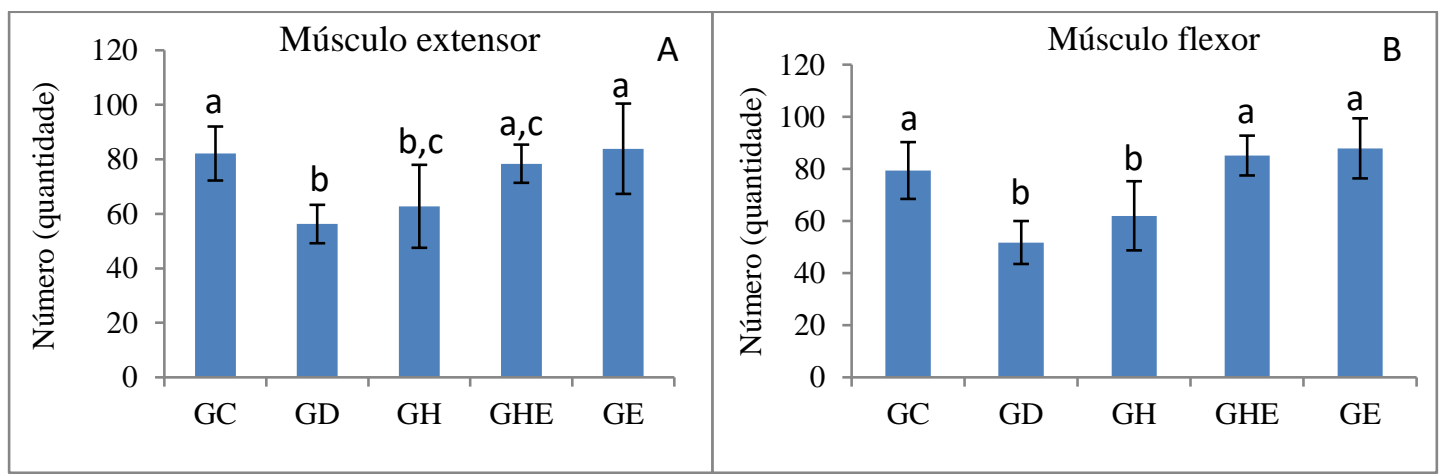

Figura 2. Número (quantidade) de fibras musculares do músculo extensor digital longo (A) e flexor digital superficial (B) dos grupos estudados - média e desvio padrão. Médias seguidas de letras diferentes são diferentes $(\mathrm{P}>0,05)$.

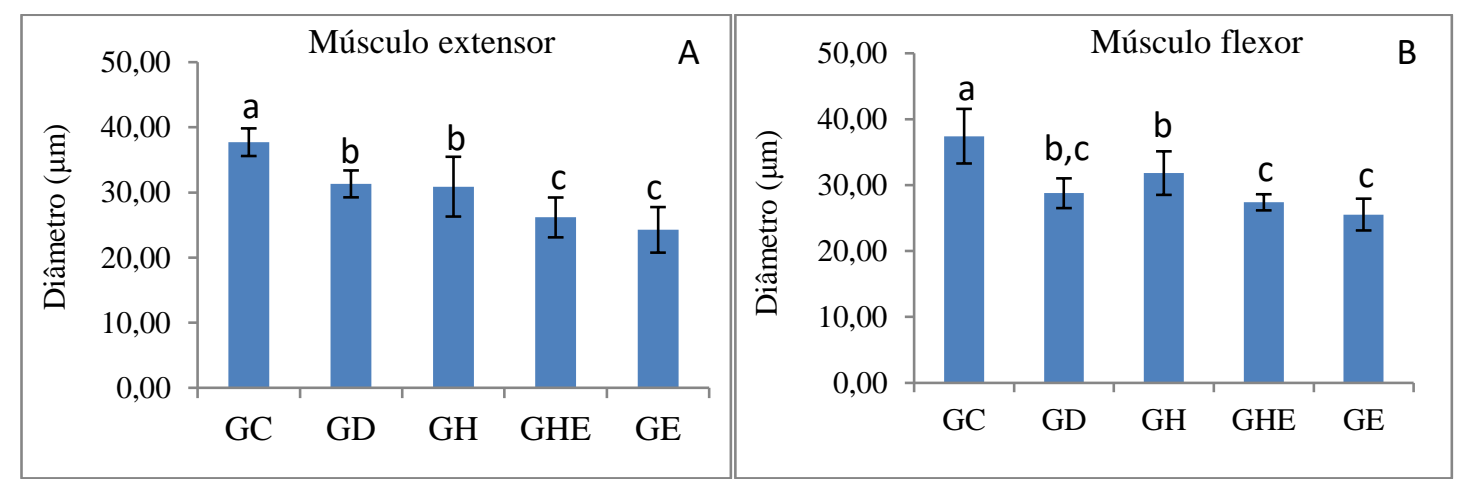

Figura 3. Diâmetro dos músculos extensor digital longo (A) e flexor digital superficial (B) dos grupos estudados - média e desvio padrão. Médias seguidas de letras diferentes são diferentes $(\mathrm{P}>0,05)$.

Ao se analisar a massa corpórea dos animais antes do procedimento cirúrgico (mi) e após os 20 dias de tratamento (mf), constata-se que os animais mantiveram seu peso mesmo após a denervação. Isso pode demonstrar que os animais não foram submetidos a nenhum tipo de desconforto ou impossibilidade de se alimentar (Tabela 1).

Com relação aos parâmetros ósseos avaliados nesta pesquisa área - A, e conteúdo mineral ósseo $\mathrm{CMO}$, apresentaram diferenças significantes entre os grupos, porém a densidade mineral óssea - DMO e a força máxima - Fmáx não apresentaram demonstrando que o período experimental não foi suficiente para alterar estas variáveis $(\mathrm{P}>0,05)$ ou pelo fato dos animais continuarem com o membro ao solo, mantendo a descarga de peso sobre o mesmo (Tabela 1). 

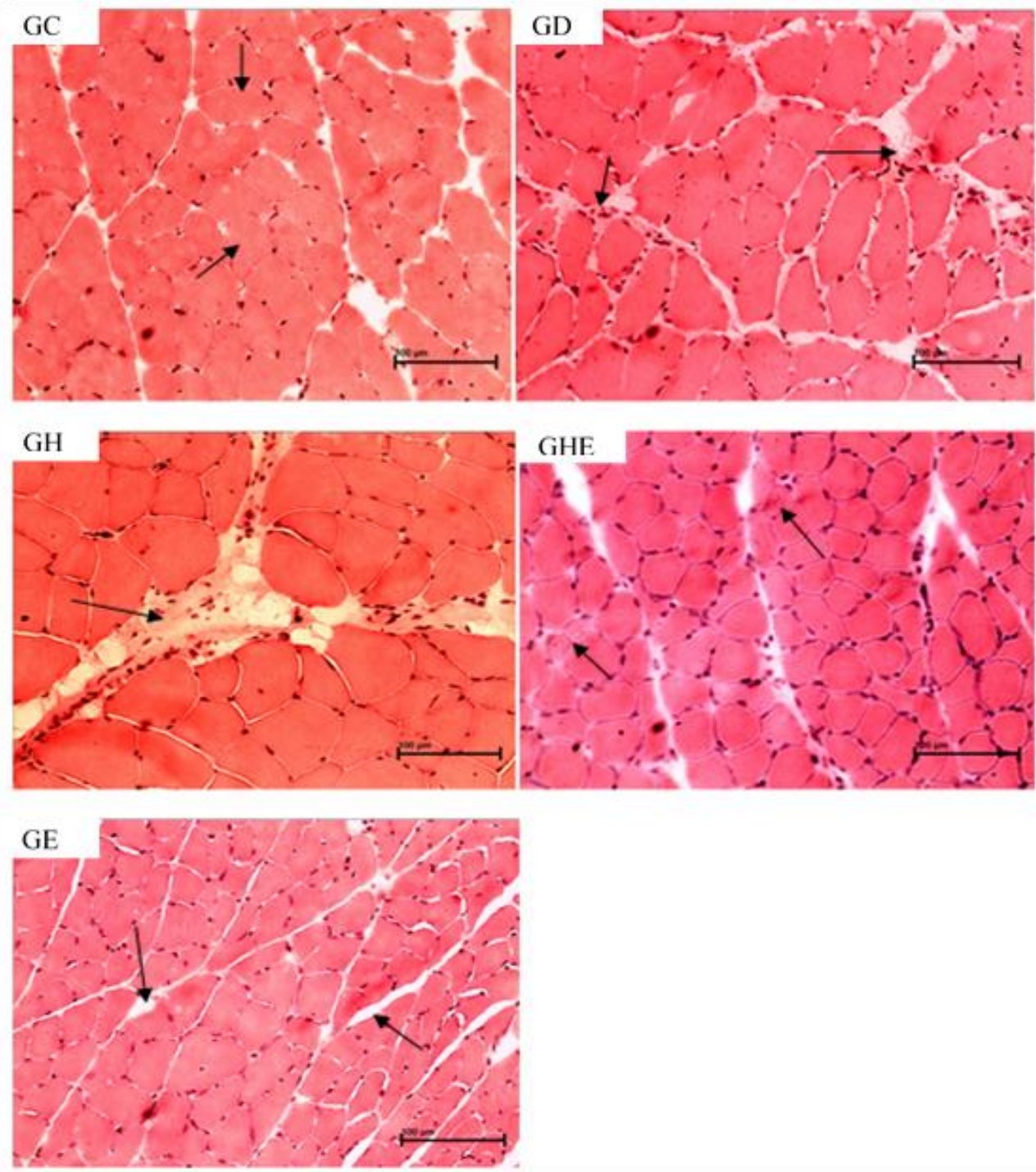

Figura 4. GC musculatura normal, com fibras alveolares (indicado pelas setas), núcleo periférico e ausência de tecido conjuntivo. GD: atrofia muscular, com diminuição na quantidade de fibras, diminuição no diâmetro das fibras, presença de infiltrado inflamatório e de tecido conjuntivo (indicado pelas setas). GH: grande aumento de tecido conjuntivo com presença de infiltrado inflamatório (seta preta), aumento no diâmetro das fibras musculares com núcleos periféricos. GHE: aumento na quantidade de fibras musculares, porém não apresenta aumento de diâmetro das fibras; fibras alveolares, presença de núcleos periféricos, novas fibras em formação (indicado pelas setas) e não se nota tecido conjuntivo e infiltrado inflamatório. GE: aumento da quantidade de fibras musculares, células alveolares e núcleos periféricos, não se nota tecido conjuntivo e infiltrado inflamatório (indicado pelas setas).

Tabela 1. Massa corpórea dos animais antes do procedimento cirúrgico (mi) e após 20 dias de tratamento (mf) e os parâmetros ósseos das tíbias dos ratos dos grupos controle (GC), denervado (GD), hidroterapia (GH), hidroterapia e eletroterapia (GHE) e eletroterapia $(\mathrm{GE})(\mathrm{P}>0,05)$.

\begin{tabular}{lccccc}
\hline Parâmetros avaliados & GC & GD & GH & GHE & GE \\
\hline mi $(\mathrm{g})$ & $0,373 \pm 0,03$ & $0,376 \pm 0,04$ & $0,377 \pm 0,04$ & $0,385 \pm 0,020$ & $0,378 \pm 0,021$ \\
mf $(\mathrm{g})$ & $0,414 \pm 0,034$ & $0,395 \pm 0,053$ & $0,402 \pm 0,045$ & $0,395 \pm 0,024$ & $0,380 \pm 0,026$ \\
& & & & & \\
Á $\left(\mathrm{cm}^{2}\right)$ & $1,387 \pm 0,108^{\mathrm{a}}$ & $1,449 \pm 0,099^{\mathrm{a}}$ & $1,375 \pm 0,113^{\mathrm{a}}$ & $1,229 \pm 0,085^{\mathrm{b}}$ & $1,153 \pm 0,072^{\mathrm{b}}$ \\
CMO $(\mathrm{g})$ & $0,276 \pm 0,026^{\mathrm{a}}$ & $0,268 \pm 0,039^{\mathrm{a}, \mathrm{b}}$ & $0,242 \pm 0,044^{\mathrm{a}, \mathrm{b}, \mathrm{c}}$ & $0,226 \pm 0,020^{\mathrm{b}, \mathrm{c}}$ & $0,217 \pm 0,008^{\mathrm{c}}$ \\
DMO $\left(\mathrm{g} / \mathrm{cm}^{2}\right)$ & $0,199 \pm 0,011$ & $0,184 \pm 0,021$ & $0,176 \pm 0,027$ & $0,184 \pm 0,011$ & $0,189 \pm 0,016$ \\
FMáx $(\mathrm{N})$ & $421,15 \pm 51,25$ & $369,91 \pm 52,93$ & $346,13 \pm 66,64$ & $345,663 \pm 86,05$ & $361,965 \pm 58,67$ \\
\hline
\end{tabular}

\section{Conclusões}


Podemos concluir diante da metodologia aplicada, que a denervação provocou atrofia muscular e o uso da eletroterapia e a associação dos dois métodos foram capazes de reverter. Já, o tratamento só com hidroterapia não alterou o quadro causado pelo processo de denervação. Com relação às propriedades ósseas, não foram observadas alterações estatisticamente significantes entre os grupos.

\section{Referência bibliográfica}

Apolinário, J. C., Coelho, W. M. D. \& Louzada, M. J. Q. (2011). Análise da influência do ultrassom de baixa intensidade na região de reparo ósseo em ratos sob ausência de carga. Fisioterapia e Pesquisa, 18(3):275-279.

Durigan, J. L. Q., Cancelliero, K. M., Dias, C. N. K., Silva, C. A., Guirro, R. R. J. \& Polacow, M. L. O. (2006). Estudo morfométrico do músculo sóleo de ratos submetidos à imobilização aguda associado à estimulação elétrica neuromuscular. Fisioterapia em Movimento, 19(2):117 - 126.

Evangelista, A. R., Gravina, G. A., Borges, F. S., Vilardi Junior, N. P. \& Petrone, N. (2003). Adaptação da característica fisiológica da fibra muscular por meio de eletroestimulação. Fisioterapia Brasil, 4(5):326-334.

Fernandes, K., Polacow, M. L., Guirro, R. R., Campos, G. E., Somazz, M. C., Pinto, V. F., . . Teodori, R. M. (2005). Análise morfométrica dos tecidos muscular e conjuntivo após desnervação e estimulação elétrica de baixa frequência. Revista Brasileira de Fisioterapia, 9(2):235-241.

Guerrino, M. R., Gonçalves, M. \& Leivas, T. P. (1996). Efeito do treinamento físico sobre a resistência óssea. Motriz, 2(1):32-36.

Medeiros, A., Oliveira, E. M., Gianolla, R., Casarini, D. E., Negrão, C. E. \& Brum, P. C. (2004). Swimming training increases cardiac vagal activity and induces cardiac hypertrophy in rats. Brazilian Journal of Medical and Biological Research, 37(12):1909-1917.

Pedro, C. R. \& Oliveira, S. P. (2009). Curso de Fisioterapia Veterinária. Instituto Brasileiro de Reabilitação Animal. ANFIVET - Associação Nacional de Fisioterapia Veterinária, 17-10.

Polônio, J. T., Mazzer, N., Barbieri, C. H. \& Mattiello-Sverzut, A. C. (2010). Eletroestimulação seletiva mantem estrutura e função do tibial anterior desnervado de ratos. Acta Ortopédica Brasileira, 18(2):85-89.

Riso, N. D. M., Ferrari, T. A., Ciarlini, L. D. R. P. \& Louzada, M. J. Q. (2010). Laser terapêutico no reparo ósseo de ratos submetidos à ausência de carga. Veterinária e Zootecnia, 17(2):250-258.

Rodrigues, M. L., Quintiliano, N. A. \& Chingui, L. J. (2011). Corrente russa versus corrente fes na reabilitação de músculos esqueléticos desnervados. Anuário da Produção de Iniciação Científica Discente, 13(16):45-55.

Salmons, S., Ashley, Z., Sutherland, H., Russold, M. F., Li, F. \& Jarvis, J. C. (2005). Functional electrical stimulation of denervated muscles: basic issues. Artificial Organs, 29(3):199-202.

Seale, P. \& Rudnicki, M. A. (2000). A new look at the origin, function, and "stem-cell" status of muscle satellite cells. Developmental Biology, 218(2):115-124.

Velho, J. R., Lins, L. A., Brum, C. S., Ribas, L. M. \& Nogueira, C. E. W. (2006). Métodos fisioterapeuticos para o tratamento de contratura de músculos flexores em potros. $X V$ Congresso de Iniciação Cientifica, 11-4.

Recebido: 13 de agosto março, 2018

Aprovado: 2 de outubro, 2018

Publicado: 5 de maio, 2019.

Licenciamento: Este artigo é publicado na modalidade Acesso Aberto sob a licença Creative Commons Atribuição 4.0 (CC-BY 4.0), a qual permite uso irrestrito, distribuição, reprodução em qualquer meio, desde que o autor e a fonte sejam devidamente creditados. 